\title{
Alendronate reduced days of bed rest and limited activity in postmenopausal women with osteoporosis and existing fractures
}

Nevitt MC, Thompson DE, Black DM, et al., for the Fracture Intervention Trial Research Group. Effect of alendronate on limited-activity days and bed-disability days caused by back pain in postmenopausal women with existing vertebral fractures. Arch Intern Med 2000 Jan 10;160:77-85.

QUESTION: In postmenopausal women with osteoporosis and $\geq 1$ vertebral fracture, does alendronate reduce back pain and functional limitation caused by back pain?

\section{Design}

3 year randomised \{allocation concealed*\} $\uparrow$, blinded \{patients, clinicians, and outcome assessors\} $\}^{*}$, placebo controlled trial (Fracture-Intervention Trial [FIT]).

\section{Setting}

11 clinical centres in the US.

\section{Patients}

2027 women who were 55-81 years of age (mean age $71 \mathrm{y}$ ), had been postmenopausal for $\geq 2$ years, had a femoral neck bone mineral density $\leqslant 0.68 \mathrm{~g} / \mathrm{cm}^{2}$, and had $\geq 1$ vertebral fracture. Follow up was $100 \%$.

\section{Intervention}

Women were allocated to alendronate sodium, 5 $\mathrm{mg} /$ day for 2 years and $10 \mathrm{mg} /$ day for the third year $(n=1022)$, or placebo $(n=1005)$.

\section{Main outcome measures}

Days of back pain and limited activity days related to back pain were assessed by questionnaire every 3 months. Physical disability related to back pain was assessed at 3 years by self report.

\section{Main results}

At 3 years, women in the alendronate group had lower cumulative incidence rates of $\geq 1$ day of bed rest $(p=0.002)$ and $\geq 7$ days of bed rest $(p<0.001)$ than did women in the placebo group; a trend toward a greater incidence of $\geq 7$ limited activity days was seen in the alendronate group $(\mathrm{p}=0.06)$ (table). The groups had similar rates of $\geq 1$ day of severe or worse back pain (relative risk reduction [RRR] 32\%, 95\% CI -3\% to 55\%) or new or worsened back disability (RRR 15\%, CI -15\% to $37 \%$ ) during follow up. After adjustment for new fractures during follow up, the effect of alendronate remained for the cumulative incidence of $\geq 7$ days of bed rest; the incidence of limited activity days was similar between groups.

\section{Conclusion}

In postmenopausal women with osteoporosis and $\geq 1$ existing vertebral fracture, alendronate reduced the days of bed rest and limited activity related to back pain.

*See glossary.

†Black DM, Cummings SR, Karpf DB, et al, for the Fracture Intervention Trial Research Group. Lancet 1996;348:1535-41.

\section{COMMENTARY}

The study by Nevitt $e t$ al reports on the first part of FIT in women with an existing vertebral fracture. ${ }^{1}$ Alendronate reduced the main outcome of vertebral fractures, which were defined by vertebral morphometry on radiography at baseline and at 36 months after randomisation (relative risk [RR] $0.53,95 \%$ CI 0.41 to 0.88 ). Alendronate also reduced the incidence of clinical vertebral fractures (RR 0.45, CI 0.27 to 0.72 ). In a related report on the same study, the groups did not differ for gastrointestinal adverse effects.

Clinicians have questioned whether vertebral fractures defined by morphometry are clinically relevant. This study shows that severe or worse back pain occurred in $56 \%$ of women with any new vertebral fractures, in $20 \%$ of those without a new vertebral fracture, and in $72 \%$ of those with a clinically evident new vertebral fracture. This finding shows that a vertebral fracture defined by morphometry is clinically relevant.

The authors found that back pain was common in the placebo group, and women in the alendronate group had $63 \%$ fewer days of bed rest because of back pain. However, the frequency of days of back pain and increases in back related physical disability did not differ at the end of the study. After controlling for the number of new vertebral fractures, alendronate had a statistically significant, beneficial effect on days of bed rest. One explanation could be that morphometry did not detect all fractures, especially mild fractures. Another limitation of the study is that the date of the true fracture is not known because radiography was done at baseline and at the end of the study.

In any event, this study shows that alendronate can reduce back pain in women.

Olof Johnell, MD, PhD Malmö University Hospital Malmö, Sweden

1 Black DM, Reiss TF, Nevitt MC, et al. Design of the fracture intervention trial. Osteoporos Int 1993;3(suppl 3):S29-39.

2 Bauer DC, Black D, Ensrud K, et al, for the Fracture Intervention Trial Research Group. Upper gastrointestinal tract safety profile of alendronate. The fracture intervention trial. Arch Intern Med 2000;160:517-25.

Alendronate $v$ placebo in postmenopausal women with osteoporosis and $\geqslant 1$ existing vertebral fracture

\begin{tabular}{lllll} 
& \multicolumn{2}{c}{ Cumulative incidence rate } & & \\
\cline { 2 - 4 } Outcomes at 3 years & Alendronate & Placebo & RRR (95\% Cl) & NNT (CI) \\
\cline { 2 - 4 }$\geqslant 1$ day of bed rest & $11 \%$ & $15 \%$ & $32 \%(13$ to 47$)$ & 23 (15 to 56$)$ \\
\hline$\geqslant 7$ days of bed rest & $4 \%$ & $9 \%$ & $56 \%(36$ to 70$)$ & 21 (17 to 32$)$ \\
\hline$\geqslant 7$ days of limited activity & $41 \%$ & $44 \%$ & $13 \%(1$ to 24$)$ & 23 (12 to 308$)$ \\
\hline
\end{tabular}

$\ddagger$ Abbreviations defined in glossary; RRR, NNT, and $\mathrm{Cl}$ were estimated from a proportional hazards model.

Source of funding: Merck Research Laboratories.

For correspondence Dr M C Nevitt, Epidemiology and Biostatistics, Prevention Sciences Group Coordinating Center-UCSF, 74 New Montgomery, Suite 600, San Francisco, CA 94105, USA. Fax +1 4155979213 